\title{
Editorial
}

\section{¿ES ÚTIL LA DISECCIÓN CADAVÉRICA EN LA ENSEÑANZA DE LA ANATOMÍA EN EL PRE-GRADO?}

\author{
Raúl A. Beltramino \\ Cátedra de Anatomía Normal. Facultad de Medicina de la Universidad Nacional de Tucumán \\ - Argentina
}

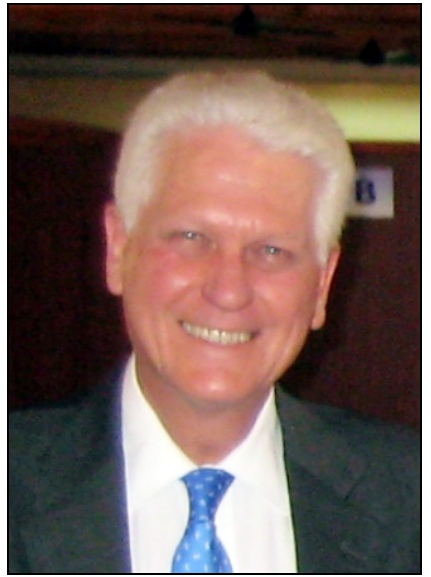

La problemática de la efectiva enseñanza de la Anatomía en el pregrado de Medicina no es un tema nuevo y en todas las reuniones científicas, congresos, jornadas, seminarios, talleres dedicados al tema en cuestión, se analiza profundamente la manera de cambiar rumbos para mejorar o maximizar dicho aprendizaje.

Desde antiguo (antes del año 300 a C.), en el Centro de Estudios de Medicina conocido como Museion o Escuela de Medicina de Alejandría, Herófilo y Erasístrato practicaron las primeras disecciones en cuerpos humanos. Se asoció la necesidad de esta práctica cadavérica por parte de los alumnos como elemento primordial e ineludible para conseguir éxito en el aprendizaje, siendo motivo de reconocido orgullo para las Cátedras de Anatomía, el poseer una importante cantidad de cadáveres para tal fin.

Es reconocido por todos los catedráticos, que la provisión de material cadavérico, fue siempre harto dificultoso, basado en factores de prejuicios por parte de los familiares del deudo así como leyes de dificultosa y burocrática aplicación efectiva, sin dejar de mencionar el costo de conservación de dicho material, ya sea se trate de cámaras frigoríficas o las consabidas tinas con formol con sus conocidas consecuencias para la salud del personal que manipula el material cadavérico. Va de suyo que a mayor población estudiantil que cursan la materia, estos inconvenientes se potencian geométricamente.

Paralelamente, debemos admitir que en los últimos años, los docentes dedicados al dictado de la materia, tratan de darle una visión mas funcional a la Anatomía, mas dinámica y sobre todo aplicado al ser vivo, alejándose paulatinamente de la enseñanza memorística, rígida, fría y detallista de la era vesaliana.

Efectuada esta introducción, se cae en la cuenta que existen situaciones de orden práctico que analizadas individualmente y en conjunto dan un punto de vista sobre la utilidad o no de la disección cadavérica por parte de los alumnos.

Es así que debemos considerar:

a) Afortunadamente la curricula de los planes de estudio para lograr el titulo de médico fueron sometidas a transformaciones, acertadas algunas, no tanto otras. Lo importante a jerarquizar es el alentador crecimiento de las carreras de postgrado para la obtención de títulos de especialistas en diferentes ramas de la Medicina. Esto conlleva la posibilidad de contar con médicos mejor preparados para la resolución de la problemática de salud de la población. Como es obvio, dicho médico debe desarrollar todo su capacidad cognitiva y de práctica asistencial, teniendo las especialidades con actividad quirúrgica relevante trascendencia a fin de no "experimentar" en el cuerpo humano su aprendizaje y destreza quirúrgica, como acontece actualmente en muchas universidades del mundo. No existe, al menos en nuestro país, reglamentación sobre la 
obligatoriedad de la práctica de la disección cadavérica en los anfiteatros de Anatomía por parte de los cursantes de post-grado en disciplinas con franco perfil quirúrgico (cirugía general, obstetricia, ginecología, traumatología, neurocirugía, otorrinolaringología, etc).

b) Uno de los flagelos que azotan a las universidades latinoamericanas, es la deserción estudiantil. Este hecho provoca una marcada pérdida de tiempo, dilapidación monetaria y capacidad ociosa de todo el andamiaje organizativo-docente en la etapa de los estudios terciarios. La Universidad Nacional de Tucumán no es ajena a este dislate y los guarismos de deserción del período 2000-2002 alcanzaron cifras del $38,4 \%$ al $46,7 \%$. O sea que poseemos una infraestructura de enseñanza (profesores, jefes de trabajos prácticos, ayudantes estudiantiles, personal no docente, material didáctico, cadáveres, estructura edilicia, etc.) que se esmera en brindar apoyo logístico para la enseñanza de la Anatomía a una población de alumnos de los cuales el $40 \%$ no obtiene su titulo de grado.

c) Otro polo de análisis es el avance, en estos últimos años, de la cirugía de transplantes de órganos cada vez mas accesible en centros sanitarios categorizados. A pesar del conocimiento de este hecho por parte de la población medianamente informada de la necesidad humanitaria de la donación de órganos, la oferta es pavorosamente inferior a las necesidades reales. Tal es la situación que datos del I.N.C.U.C.A.I. (Instituto Nacional Centro Único Coordinador Ablación e Implante) revelan que existen en la Argentina, al menos 7 a 8 mil pacientes en lista de espera para algún tipo de transplante. Un alto porcentaje de estos pacientes, fallecen en espera de algún dador.

d) Las comunicaciones tuvieron un vuelco espectacular jamás imaginado a partir de la creación de las computadoras, tecnología que en la actualidad es un arma formidable en el terreno del conocimiento científico. Curiosamente cuando se menciona la metodología de la enseñanza, las diferentes opciones que se detallan en orden de prioridad son: clases magistrales, trabajos prácticos, talleres, tutorías, mostraciones cadavéricas, consultas con docentes de la cátedra pero llama la atención la escasa mención que se hace de la informática como herramienta de comunicación y aprendizaje. Existen en muchas universidades del mundo, programas de post-grado interactivos "en línea", aun algunos de ellos con uso de "modelos" humanos para el aprendizaje. Es casi imposible imaginar como será nuestro mundo en los próximos 20 años gracias al avance de la computación..

Corresponde entonces desmenuzar cada punto mencionado:

A) La formación de post-grado debe ser de inexcusable excelencia y el titulo de especialista en materias quirúrgicas debe reflejar el correcto conocimiento en el arte de curar, debe en consecuencia efectuar la práctica del aprendizaje anatómico obligatoria y reglamentado, en el anfiteatro de las cátedras de Anatomía, bajo la supervisión del personal docente preparado. Es obvio que ningún profesional deserta luego de conseguir su título de grado, contrariamente a la deserción estudiantil. Como conclusión lógica, las cátedras que permiten la disección cadavérica por parte de los estudiantes, los cuales tienen una tasa de deserción antes mencionada $(40 \%)$, tendrían una pérdida de infraestructura docente del $40 \%$. (interprétese como desaprovechamiento del material cadavérico). Esto tiene un costo demasiado alto para analizarlo como tema menor y es inadmisible en Argentina $y$ en las circunstancias actuales.

B) Desde un punto de vista mas humanitario que docente y despojándose de egoísmos propios que invaden al ser humano: ¿no sería mejor que algún órgano de ese cuerpo yermo sea utilizado para salvar una vida antes de terminar en la mesa de disección ?.

C) Sin dejar de reconocer la validez y utilidad relativa de la disección cadavérica por parte del estudiante, es obligación generacional aceptar que se pueden aprender las estructuras anatómicas sin disecar cadáveres en el pre-grado. En las principales bibliotecas médicas del mundo moderno existen programas interactivos con "software" en los cuales se visualiza con meridiana claridad estructuras anatómicas aun con animación que dejan una clara enseñanza al alumno.

Por lo tanto se debe jerarquizar la premisa que no es imprescindible la disección cadavérica por parte del alumno de pre-grado que pretende estudiar el cuerpo humano siendo suficiente el aporte de todos los otros métodos didácticos mencionados, dejando la obligatoriedad de la práctica de disección para los estudiosos de la Anatomía y de los profesionales que cursan un post-grado de orientación quirúrgica. 
Cabe una última reflexión en vista de lo expuesto:

"Las mentes grandes discuten ideas", las mentes promedio, discuten los eventos, las mentes pequeñas discuten las personas"

Estoy absolutamente persuadido que debemos ubicarnos en el primer renglón. 